\title{
Effect of Surface State on Nodular Corrosion Resistance of Zircaloy-4 Alloy
}

\author{
Chuan-Ming Chen $\cdot$ Bang-Xin Zhou $\cdot$ Shao-Qiu Gou $\cdot$ Jiao Huang $\cdot$ Mei-Yi Yao
}

Received: 23 May 2014/Revised: 12 July 2014/Published online: 3 January 2015

(C) The Chinese Society for Metals and Springer-Verlag Berlin Heidelberg 2015

\begin{abstract}
The effect of surface state on the nodular corrosion resistance of Zircaloy-4 alloy was investigated in superheated steam at $500{ }^{\circ} \mathrm{C} / 10.3 \mathrm{MPa}$ by autoclave tests. The microstructures of oxide films on the corroded specimens were observed by TEM and SEM. The results indicate that surface strained layer delays the appearance of nodular spots on the specimen surfaces and improves the nodular corrosion resistance. The columnar grains orientation of the oxide films formed on the specimens with surface strained layer was more consistent than that on the specimens without surface strained layer when a comparison was made on the same orientation of the grain surfaces. Such a kind of oxide microstructure formed on the specimens with surface strained layer can hinder the diffusion of oxygen ions along the grain boundaries and delay the growth of oxide films, therefore retard the formation process of nodular spots. This indicates that the microstructure of the initial oxide films has an important influence on the subsequent growth of the oxide films.
\end{abstract}

KEY WORDS: Zircaloy-4; Surface strained layer; Nodular corrosion resistance; Microstructures

\section{Introduction}

Zirconium alloys are used as nuclear fuel cladding materials owing to their low thermal neutron absorption crosssection and high corrosion resistance [1-4]. In order to reduce the cost of nuclear power, it is necessary to increase the burn-up of nuclear fuel and extend refueling cycle. Consequently, higher corrosion resistance of zirconium alloys is required [5]. In general, the growth of uniform oxide films is observed usually in pressurized water

Available online at http://link.springer.com/journal/40195

C.-M. Chen · B.-X. Zhou $(\bowtie) \cdot$ S.-Q. Gou · J. Huang ·

M.-Y. Yao

Laboratory for Microstructures, Shanghai University, Shanghai

200444, China

e-mail: zhoubx@shu.edu.cn

C.-M. Chen · B.-X. Zhou - S.-Q. Gou - J. Huang · M.-Y. Yao Institute of Materials, Shanghai University, Shanghai 200072, China reactors (PWRs). Alongside with the uniform corrosion of zirconium alloys, nodular corrosion is observed under some definite conditions [6]. Nodular corrosion is a problem in boiling water reactors (BWRs). The lenticular oxide nodules are observed gray and are dozens of times $(\sim 100 \mu \mathrm{m})$ thicker than the black oxide films [7]. With the growth of nodular corrosion spots, the local cladding is rather quickly thinned [8], and hydrogen uptake increases, which shortens the service life of nuclear fuel cladding. Therefore, nodular corrosion of Zircaloy fuel claddings has to be concerned $[9,10]$. Several physical mechanisms involving the formation of nodular corrosion have been proposed, but it is still unclear how nodular oxide is formed. In Ref. [11], it was suggested that $\mathrm{H}_{2}$ was mainly produced at the oxide/metal $(\mathrm{O} / \mathrm{M})$ interface. When the pressure of $\mathrm{H}_{2}$ gas accumulated in the $\mathrm{O} / \mathrm{M}$ interface exceeded the pressure the oxide film could withstand, the oxide film would break to initiate nodular corrosion. Cheng et al. [12] reported that the sites of nodular oxide nucleation were found not to be at large precipitates or grain boundaries; rather, the sites were identified, though not 


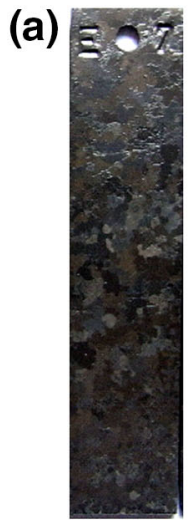

$1 \mathrm{~h}$

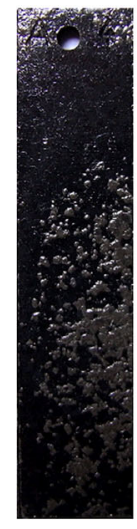

$7 \mathrm{~h}$

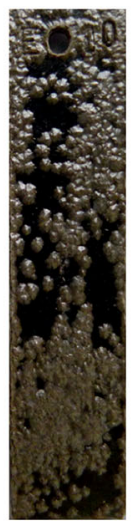

$30 \mathrm{~h}$ (b)

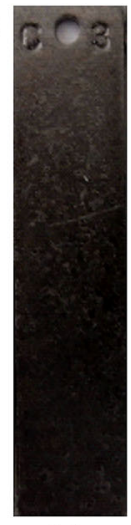

$1 \mathrm{~h}$

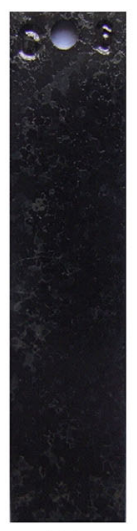

$7 \mathrm{~h}$

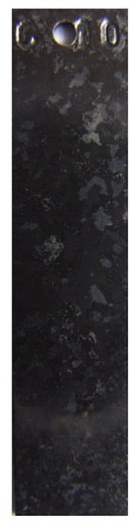

$30 \mathrm{~h}$

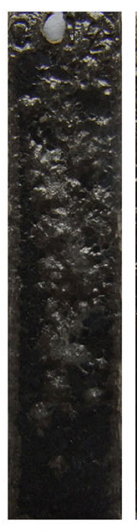

$100 \mathrm{~h}$

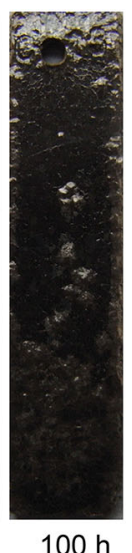

$100 \mathrm{~h}$

Fig. 1 Surface morphologies of Zircaloy-4 specimens without a and with b surface strained layer corroded in superheated steam at $500{ }^{\circ} \mathrm{C} / 10.3 \mathrm{MPa}$ for different time

unambiguously, to be free of precipitates. Zhou et al. [13] proposed a nucleation and growth model - at the first stage of oxidation, epitaxial oxide films formed on the metal surface in different thicknesses were due to the differences in grain orientation or badly distributed alloy elements. Optimizing alloying composition [14] and thermal treatment process [15] are commonly used to improve the uniform corrosion resistance and nodular corrosion resistance. Since the mechanism of nodular corrosion is still unclear, other ways to improve the nodular corrosion resistance cannot be ruled out. In this paper, a comparison study on the presence and absence of surface strained layer on Zircaloy-4 specimens is carried out to explore nodular spots formation and the corresponding mechanism.

\section{Experimental}

To observe the formation and development process of nodular corrosion spots on the surface of a single grain, coarse-grained Zircaloy-4 specimens without textures should be prepared. Based on previous work [16], the flat Zircaloy-4 specimens of $35 \mathrm{~mm} \times 10 \mathrm{~mm}$ in dimension were cut from an as-received 1-mm-thick plate, vacuum-sealed in quartz capsules, annealed at $1,030{ }^{\circ} \mathrm{C}$ for $40 \mathrm{~min}$ and then quenched into water by simultaneously breaking the quartz capsules. The specimens were vacuum-annealed again at $800{ }^{\circ} \mathrm{C}$ for $10 \mathrm{~h}$ to obtain the coarse grains of $0.4-0.8 \mathrm{~mm}$ in diameter. Annealing at $700{ }^{\circ} \mathrm{C}$ in vacuum for $100 \mathrm{~h}$ was adopted to reduce the supersaturated solid solution of alloying elements in the $\alpha$-Zr matrix. Before every annealing, the specimens were pickled in a solution of $10 \mathrm{vol} \% \mathrm{HF}+45 \mathrm{vol} \% \mathrm{HNO}_{3}+45 \mathrm{vol} \% \mathrm{H}_{2} \mathrm{O}$, then rinsed in cold tap water and deionized water to get a cleaned surface.

The prepared specimens were divided into two groups: One group of specimens was grinded with 2000\# sandpaper, and another group of specimens was not grinded for comparison. The corrosion tests for these specimens were performed in a static autoclave with superheated steam at $500{ }^{\circ} \mathrm{C} / 10.3 \mathrm{MPa}$. The weight gain was a mean value obtained from seven specimens. Prior to corrosion tests, the two batches of specimens were cleaned and pickled in a solution of $10 \mathrm{vol} \% \mathrm{HF}+45 \mathrm{vol} \% \mathrm{HNO}_{3}+45 \mathrm{vol} \%$ $\mathrm{H}_{2} \mathrm{O}$, sequentially rinsed in cold tap water and finally rinsed in boiling deionized water.

The compositions of $1.34 \mathrm{wt} \% \mathrm{Sn}, 0.14 \mathrm{wt} \% \mathrm{Fe}$, $0.09 \mathrm{wt} \% \mathrm{Cr}$ and balance of $\mathrm{Zr}$ for Zircaloy- 4 specimens were obtained by inductively coupled plasma atomic emission spectrometry(IC-PAES) analysis. JSM-6700F scanning electron microscope (SEM) was employed to examine the morphology of the fractured surface and the outer surface of oxide films formed on the specimens after corrosion. The preparation process of the fracture surface and outer surface samples has been described in Ref. [18] in detail. In order to improve the quality of images, a thin Pt layer was deposited on the oxide samples by sputtering. The microstructure of oxide films was examined by JEM2010F transmission electron microscope (TEM) [19-22]. The TEM cross-sectional sample of oxide films was prepared by 600i dual-beam focused ion beam (FIB) [23-25].

\section{Results and Discussion}

\subsection{Corrosion Behavior}

Figures 1 and 2, respectively, are surface morphology and corrosion weight gain as a function of exposure time after the autoclave tests in superheated steam at $500{ }^{\circ} \mathrm{C} / 10.3 \mathrm{MPa}$ for two groups of specimens. The specimens without surface strained layer were covered with considerable nodular spots, and the coverage was about $70 \%$ after $30 \mathrm{~h}$ exposure as shown in Fig. 1a; while the specimens with strained layer 


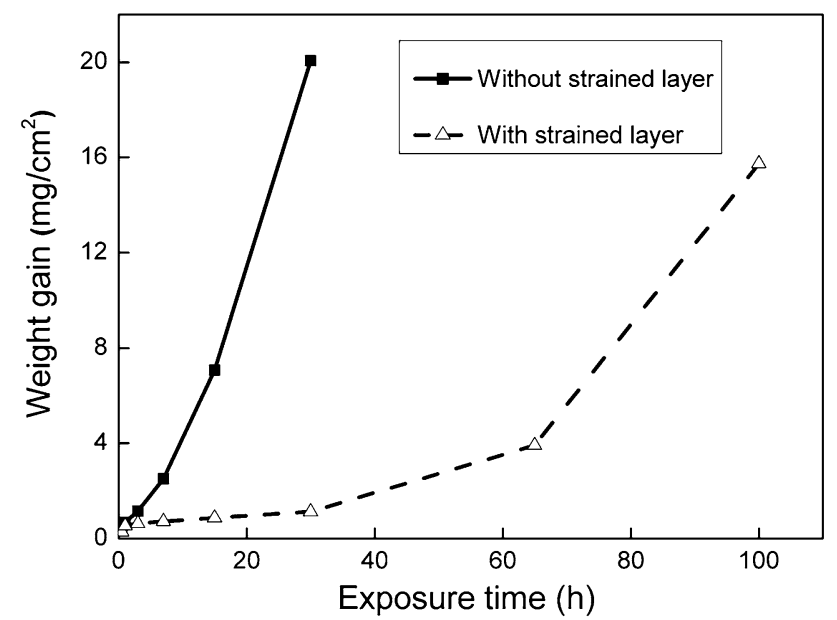

Fig. 2 Weight gain versus exposure time of Zircaloy-4 specimens without and with surface strained layer corroded in superheated steam at $500{ }^{\circ} \mathrm{C} / 10.3 \mathrm{MPa}$

were covered with only a few nodular spots after the same exposure time as shown in Fig. 1b. After 100-h exposure, the nodular spots on the surface of the specimens with strained layer increased, and the coverage of nodular spots was different among the same group of specimens, ranging from about $40 \%$ to $60 \%$. This may be due to the difference of the strained layer thickness on the specimen surface. After 30-h exposure, the corrosion weight gain of the specimens with strained layer was about $1.0 \mathrm{mg} / \mathrm{cm}^{2}$, while the corrosion weight gain of the specimens without strained layer was about $22 \mathrm{mg} / \mathrm{cm}^{2}$ (Fig. 2). The corrosion rate of the specimens without strained layer is significantly larger than that of the specimens with strained layer.

\subsection{Morphology of Oxide Films}

Figure 3 is the outer surface morphologies of oxide films formed on Zircaloy-4 specimens with different surface states corroded in superheated steam at $500{ }^{\circ} \mathrm{C} / 10.3 \mathrm{MPa}$ for $0.5 \mathrm{~h}$. On the surface of the specimens without strained layer, some bumps and cracks were observed, while on the surface of the specimens with strained layer, fluctuation and chapped phenomenon was not obvious. Bumps would grow faster and develop into nodular corrosion spots in further corrosion and cracks that existed on the bumps damaged the protection of oxide films, all are harmful to the corrosion resistance.

Figure 4 shows the fracture surface morphologies of oxide films formed on Zircaloy-4 specimens with different surface states corroded in superheated steam at $500{ }^{\circ} \mathrm{C} / 10.3 \mathrm{MPa}$ for $7 \mathrm{~h}$. It is obvious that the oxide film of the specimen without strained layer (approximately $6.10 \mu \mathrm{m}$ ) is thicker than that with strained layer with more micro-cracks and pores.

Figure 5 shows the TEM images and selected area electron diffraction patterns (SAEDPs) of the specimens without and with surface strained layer corroded in superheated steam at $500{ }^{\circ} \mathrm{C} / 10.3 \mathrm{MPa}$ for $0.5 \mathrm{~h}$. SAEDPs in Fig. 5a and $\mathrm{c}$ show the grain surface orientations of metal matrix without and with strained layer are the same, i.e., (1011) plane. According to the results obtained by Zhou et al. [16] using Zircaloy-4 coarse-grained specimens corroded in superheated steam at $500{ }^{\circ} \mathrm{C}$, such crystal orientation of grain surface is easy to develop into nodular spots after 12-h exposure. Therefore, it is appropriate to investigate the microstructure difference of the oxide films formed on grain surfaces with such orientation before the appearance of nodular spots to better understand the mechanism of the effect of surface state on the nodular corrosion resistance.

Figure $5 \mathrm{~b}$ and $\mathrm{d}$ are the dark-field images of oxide films formed on the specimens without and with strained layer corroded for $0.5 \mathrm{~h}$, the $\mathrm{O} / \mathrm{M}$ interface is marked by dashed line. The morphologies of the columnar grains could be
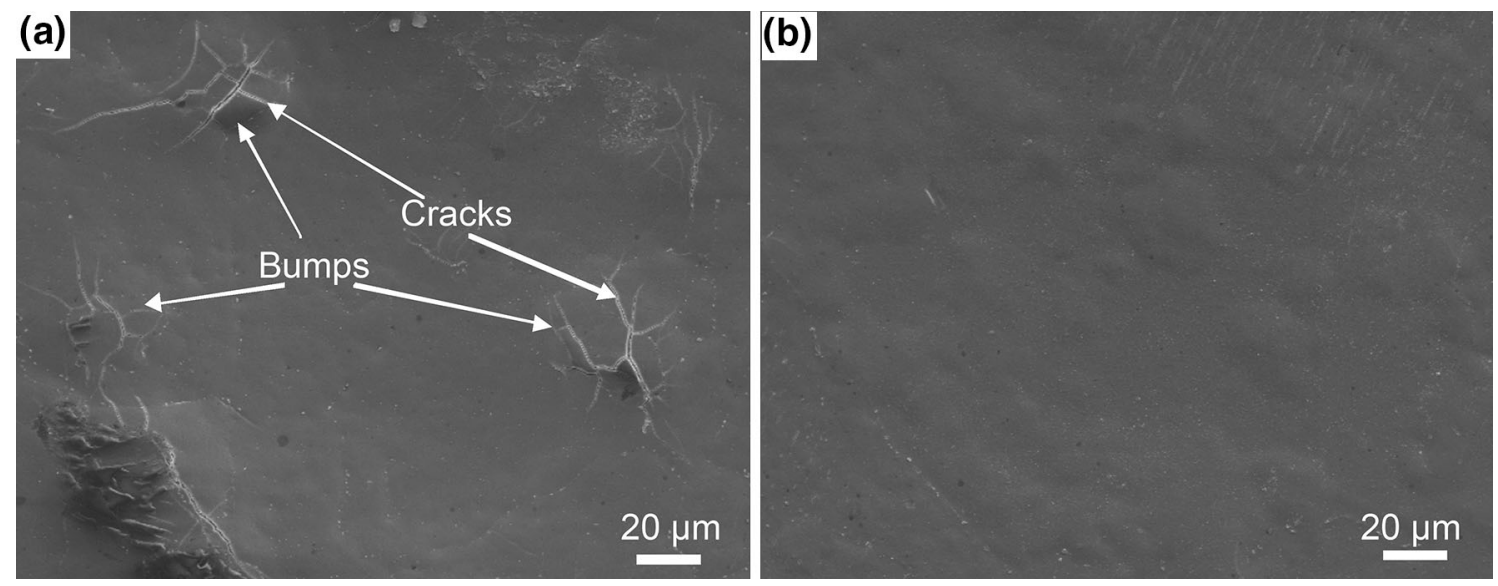

Fig. 3 Outer surface morphologies of oxide films formed on Zircaloy-4 specimens without a and with b surface strained layer corroded in superheated steam at $500{ }^{\circ} \mathrm{C} / 10.3 \mathrm{MPa}$ for $0.5 \mathrm{~h}$ 

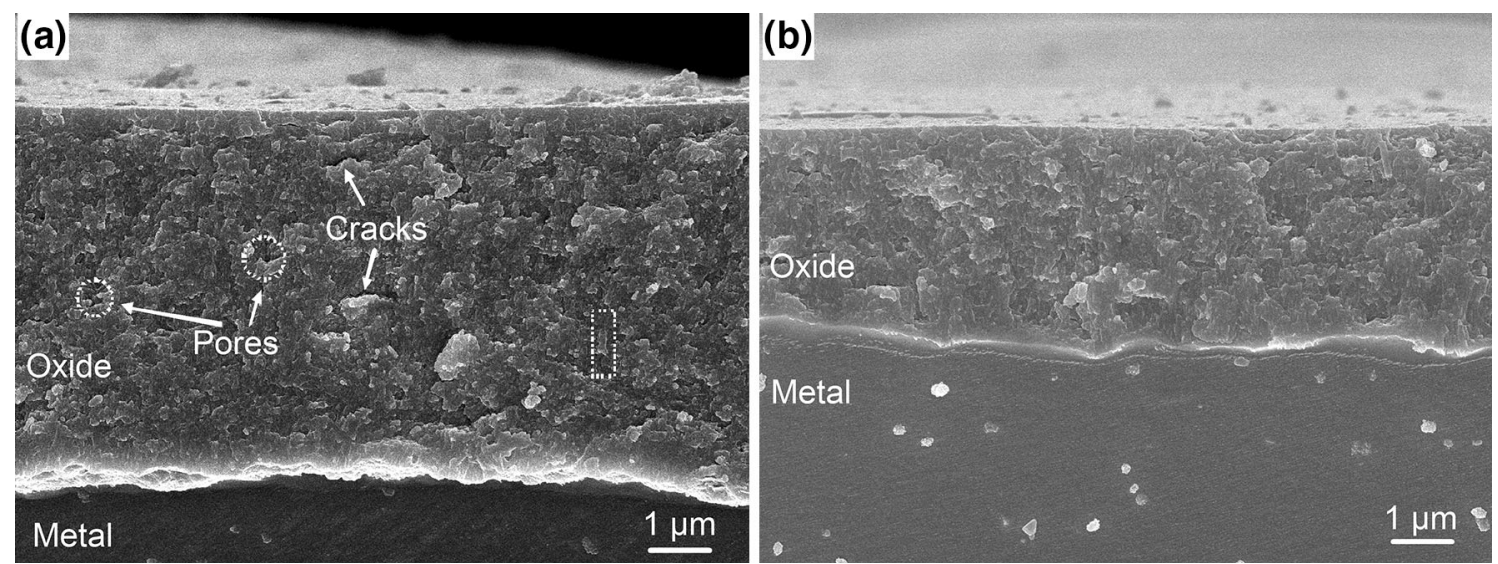

Fig. 4 Fracture surface morphologies of oxide films formed on Zircaloy-4 specimens without a and with $\mathbf{b}$ surface strained layer corroded in superheated steam at $500{ }^{\circ} \mathrm{C} / 10.3 \mathrm{MPa}$ for $7 \mathrm{~h}$
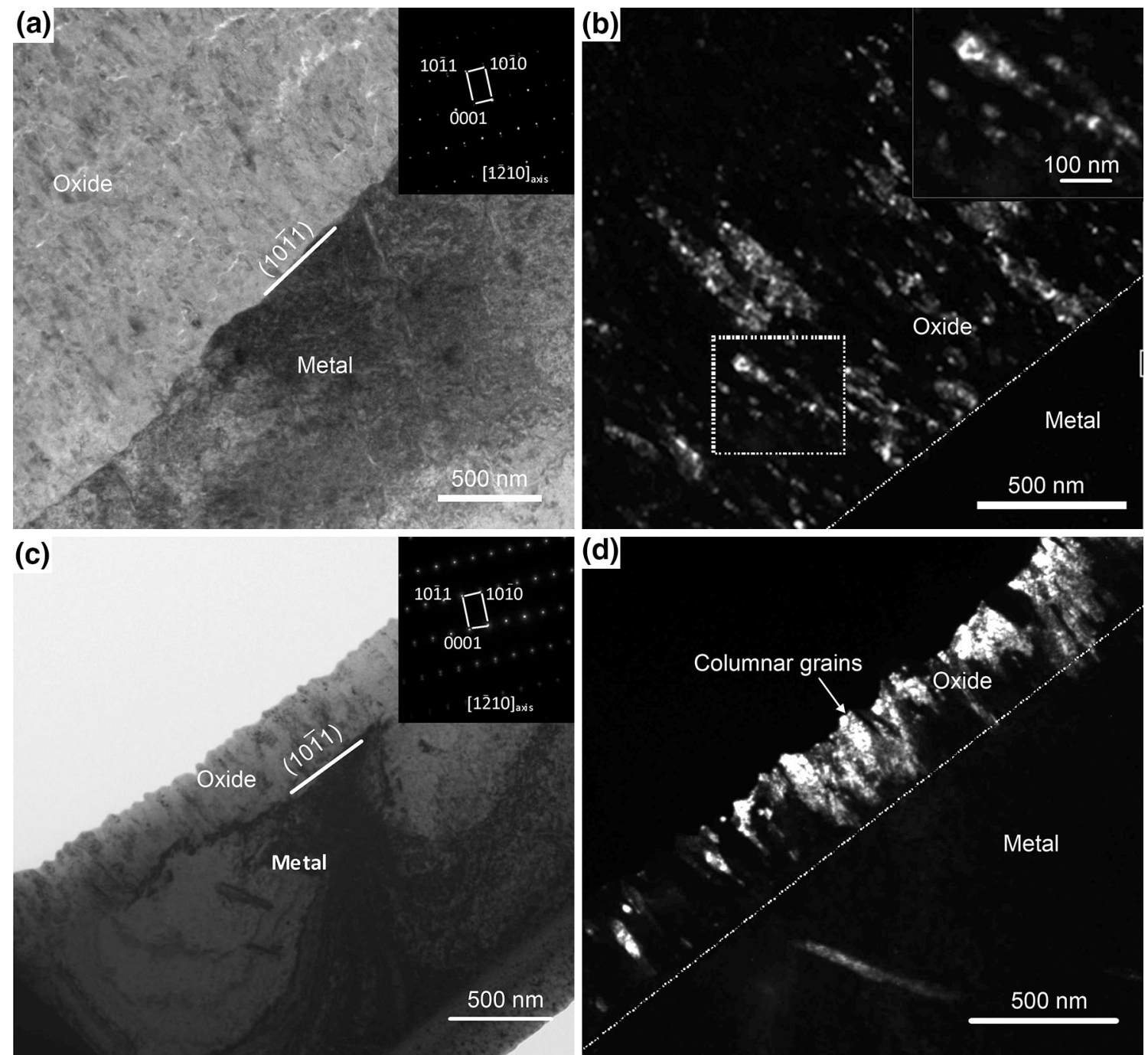

Fig. 5 Bright-field TEM images showing the orientations of metal grains a, $\mathbf{c}$ and dark-field TEM images showing the oxide films formed on the grains $\mathbf{b}, \mathbf{d}$ of the specimens without $\mathbf{a}, \mathbf{b}$ and with $\mathbf{c}, \mathbf{d}$ surface strained layer corroded in superheated steam at $500{ }^{\circ} \mathrm{C} / 10.3 \mathrm{MPa}$ for $0.5 \mathrm{~h}$ 


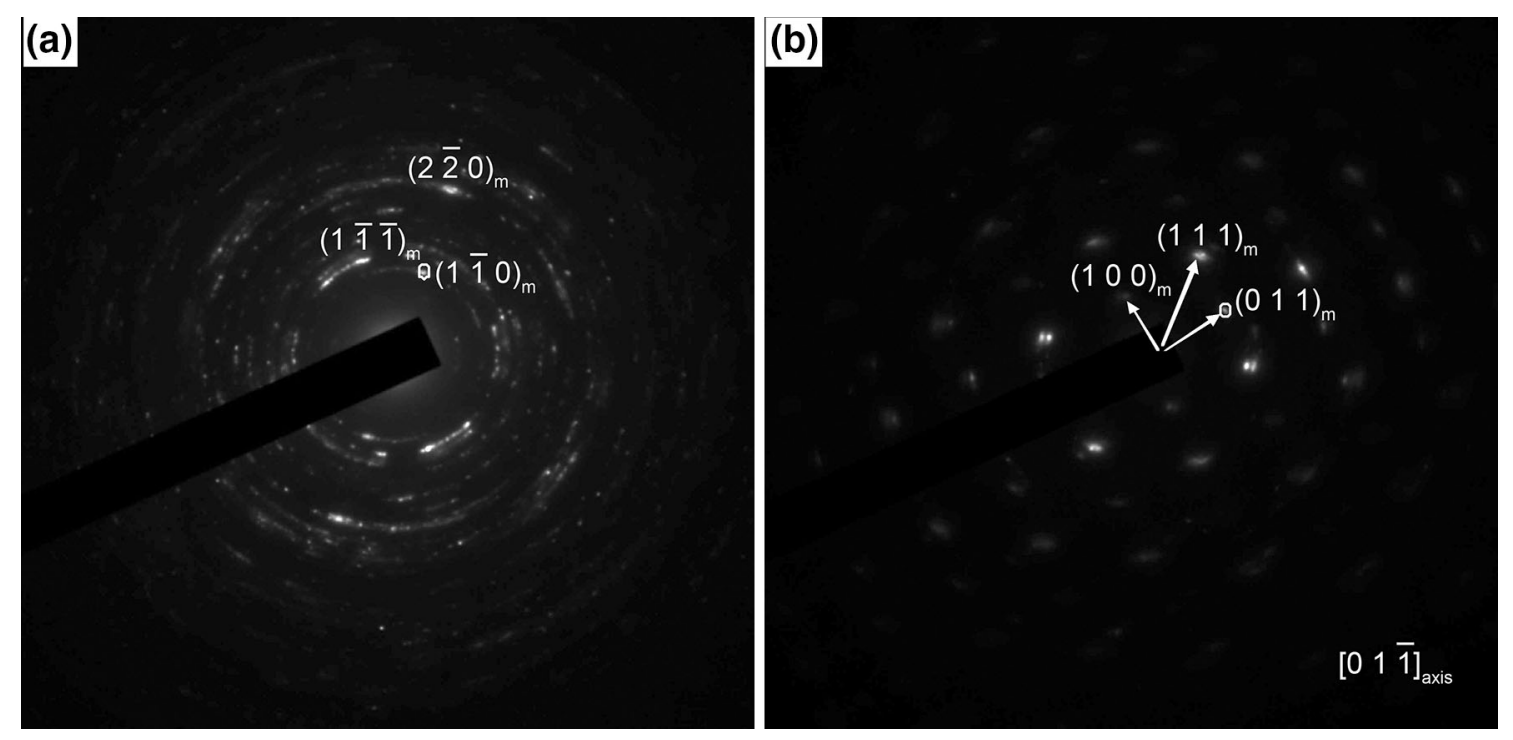

Fig. 6 SAED patterns of oxide films formed on the grains without a and with $\mathbf{b}$ surface strained layer corroded in superheated steam at $500{ }^{\circ} \mathrm{C} / 10.3 \mathrm{MPa}$ for $0.5 \mathrm{~h}$ (the diffraction spots are selected in the dark-field images of oxide films in Fig. 5b, d, which are circled)

observed from bright and dark contrast in the dark-field image. Due to the presence of the sub-grains, the "specks" with different contrast were also found inside the columnar grains, and the size of sub-grains was only about $40 \mathrm{~nm}$ as shown in a higher magnification image inset the upper right of Fig. 5b. Under the same imaging conditions, the columnar grains with a similar orientation should have the same contrast. Therefore, it is noticed from Fig. $5 b$ and d that there is a significant difference of the microstructure in the oxide layers formed on the specimens without and with strained layer. The oxide films formed on the specimens with surface strained layer is relatively thinner, simultaneously, the orientation of the columnar grains is more consistent (Fig. 5d). In contrast, the orientation difference of columnar grains and sub-grains inside the oxide films formed on the specimen surface without strained layer is larger (Fig. 5b).

The selected area electron diffraction patterns (SAD) presented in Fig. 6 show the information of crystal structure and orientation of the oxide films formed on the specimens without and with strained layer. It is noted that the crystal structure is mainly monoclinic [26] as indicated in the patterns. A nearly continuous diffraction rings are obtained in the SAD pattern of the oxide films formed on the specimens without surface strained layer (Fig. 6a), which illustrates that the orientation of oxide grains is distributed in a scattered manner. However, the SAD pattern of the oxide films formed on the specimens with surface strained layer is like a single crystal diffraction pattern as shown in Fig. 6b, which indicates that the orientation distribution of oxide grains is rather concentrated. These results are consistent with the observation of dark-field images of oxide grains as shown in Fig. 5b, d.
When zirconium is corroded in high-temperature water or superheated steam, $\mathrm{O}^{2-}$ or $\mathrm{OH}^{-}$diffuses from outside of oxide into $\mathrm{O} / \mathrm{M}$ interface and reacts with zirconium to form $\mathrm{ZrO}_{2}$ during the oxidation process, while electrons diffuse along the opposite direction [27]. Therefore, the microstructure of oxide films (such as the size, shape and orientation of the oxide grains, pores and micro-cracks in the oxide films, and the second phase precipitates) will certainly influence the growth of oxide films, and affect the corrosion resistance of zirconium alloys in turn. Zhou et al. $[28,29]$ studied the effect of alloying compositions and water chemistry conditions on the corrosion resistance of zirconium alloys and discussed the relationship between the microstructural evolution of oxide films and corrosion resistance, it is pointed out that due to the P.B. ratio of $\mathrm{Zr}$ (1.56), a compressive stress was produced in the oxide film, many defects would be generated during the formation of the oxide under such conditions. The diffusion, annihilation and condensation of vacancies and interstitials under the action of stress and temperature lead to the stress relaxation in the oxide films. The vacancies were absorbed by grain boundaries to form many pore clusters which further developed into micro-cracks under stress, meanwhile, columnar grains evolved into equiaxed grains. Such kind of microstructural evolution will lead to the enhancement of oxygen ions diffusion and the acceleration of the oxide film growth.

According to Refs. [13, 30], nucleation and growth model - at the first stage of oxidation, epitaxial oxide films formed on the metal surface in different thicknesses are due to the differences in grain orientation. A compressive stress forms in the oxide film, and a tensile stress will be produced in the metal underneath the oxide film. The metal 
substrate below the oxide/metal interface covered with thicker oxide film develops deformation due to the larger tensile stress, then increases the dislocation density of metal substrate and diffusion channels of oxygen ions, finally accelerates corrosion rate and leads to the formation of bump in the black oxide films. The bumps act as nuclei of nodular corrosion, simultaneously, the vacancies in the bumps diffuse directionally and condense to form transverse cracks under the compressive stress, forming nodular spots. In light of the above discussion, it is easy to understand the results obtained in present work. When the oxide film is formed on the surface of the specimen without strained layer, the orientation difference of the columnar grains and sub-grains in the oxide film is relatively larger. Such kind of microstructure increases diffusion channels of oxygen ions. Therefore, the oxide film becomes thicker, under which the metal substrate suffers a larger tensile stress. Then, the dislocation density and oxygen ions diffusion channels in metal substrate increase inevitably. This finally accelerates the corrosion rate and leads to the formation of lump. When oxide film is formed on the surface of the specimen with strained layer, the columnar grains with relatively consistent crystal orientation are formed. Such kind of microstructure is not favorable to the diffusion of oxygen ions along grain boundaries and also delays the microstructural evolution of the oxide films, and thus, the growth rate of oxide film is relatively slower and nodular corrosion resistance of the specimens is also improved accordingly. It is also demonstrated that the microstructure of the initial oxide films has an important influence on the subsequent growth of oxide films, which also proves that the microstructural evolution of the oxide films is a key factor in affecting the growth rate of the oxide films and the corrosion resistance of zirconium alloys.

\section{Conclusions}

When Zircaloy- 4 specimens were corroded in superheated steam at $500{ }^{\circ} \mathrm{C} / 10.3 \mathrm{MPa}$, the strained surface layer could delay the development of nodular corrosion spots and significantly improve the nodular corrosion resistance. The orientation of columnar grains in the initial oxide film formed on the specimens with surface strained layer is more consistent than that of the specimens without surface strained layer when the comparison is made on the same orientation of the grain surfaces. Such a kind of microstructure of the oxide films formed on the specimens with surface strained layer is not favorable to the diffusion of oxygen ions along the grain boundaries, therefore delays the growth of the oxide films and retards the formation of nodular spots subsequently. This indicates that the microstructure differences of the initial oxide films have substantial influence on the subsequent growth of the oxide films.

Acknowledgments The authors would like to express their thanks to Dr. Pengfei Hu, Mr. Jianchao Peng and Mrs. Xue Liang of Instrumental Analysis and Research Center of Shanghai University for help in the microstructural analysis and FIB preparation. This study was financially supported by the National Natural Science Foundation of China (No. 51171102).

\section{References}

[1] P. Billot, S. Yagnik, N. Ramasubramanian, J. Peybernes, D. Pecheur, paper present in Zirconium in the Nuclear Industry: 13th International Symposium, West Conshohocken, 2002, pp. $169-189$

[2] A.T. Motta, A. Yilmazbayhan, M.J. Gomes da Silva, R.J. Comstock, G.S. Was, J.T. Busby, E. Gartner, Q.J. Peng, Y.H. Jeong, J.Y. Park, J. Nucl. Mater. 371, 61 (2007)

[3] V. Nikulina, P.P. Markelov, M.M. Peregud, J. Nucl. Mater. 238, 205 (1996)

[4] J.P. Mardon, D. Charquet, J. Senevat, paper present in Zirconium in the Nuclear Industry: 12th International Symposium, West Conshohocken, 2000, pp. 505-524

[5] P. Bossis, D. Pecheur, K. Hanifi, J. Thomazet, M. Blat, J. ASTM Int. 3, JAI12404 (2006)

[6] B. Cox, J. Nucl. Mater. 336, 331 (2005)

[7] K. Ogata, Y. Mishima, T. Okubo, T. Aoki, T. Hattori, T. Fujibayashi, M. Inagaki, K. Murota, T. Kodama, K. Abe, paper present in Zirconium in the Nuclear Industry: 8th International Symposium, Philadelphia, 1989, pp. 291-314

[8] B. Cheng, R.B. Adamson, paper present in Zirconium in the Nuclear Industry: 7th International Symposium, Philadelphia, 1987, pp. 206-223

[9] V.V. Likhanskii, I.A. Evdokimov, J. Nucl. Mater. 392, 447-452 (2009)

[10] A.B. Johnson, R.M. Horton, paper present in Zirconium in the Nuclear Industry: 3th International Symposium, Quebec City, Canada, 1977, pp. 295-311

[11] R. Kuwae, K. Sato, E. Higashinakagawa, J. Kawashima, S. Nakamura, J. Nucl. Mater. 119, 229 (1983)

[12] B. Cheng, R.B. Adamson, paper present in Zirconium in the Nuclear Industry: 7th International Symposium, Philadelphia, 1987, pp. 387-416

[13] B.X. Zhou, J. Nucl. Sci. Eng. 13, 51 (1993)

[14] Y.H. Jeong, S.Y. Park, M.H. Lee, B.K. Choi, J.H. Baek, J.Y. Park, J.H. Kim, H.G. Kim, J. Nucl. Sci. Technol. 43, 977 (2006)

[15] B.G. Parfenov, V.V. Gerasimov, G.I. Venediktova, Corrosion of zirconium and zirconium alloys (Atomizdat, Moscow, 1969)

[16] B.X. Zhou, J.C. Peng, M.Y. Yao, Q. Li, S. Xia, C.X. Du, G. Xu. Paper present in Zirconium in the Nuclear Industry: 16th International Symposium, West Conshohocken, 2010, pp. 620-646

[17] X.Y. Zhong, B. Yang, M.C. Li, M.Y. Yao, B.X. Zhou, J.N. Shen, Rare Metal Mater. Eng. 39, 2165 (2010). (in Chinese)

[18] B.X. Zhou, Q. Li, M.Y. Yao, W.Q. Liu, Y.L. Chu, paper present in Zirconium in the Nuclear Industry: 15th International Symposium, West Conshohocken, 2009, pp. 360-383

[19] H. Anada, K. Takeda, paper present in Zirconium in the Nuclear Industry: 11th International Symposium, West Conshohocken, 35-54, 1996

[20] G.M. McDougall, V.F. Urbanic, paper present in Zirconium in the Nuclear Industry: 13th International Symposium, West Conshohocken, 2002, pp. 247-273 
[21] H.G. Kim, Y.H. Jeong, T.H. Kim, J. Nucl. Mater. 326, 125 (2004)

[22] B. Wadman, Z. Lai, H.O. Andrén, A.L. Nyström, P. Rudling, H. Pettersson, paper present in Zirco-nium in the Nuclear Industry: 10th International Symposium, Philadelphia, 1994, pp. 579-598

[23] D.J. Larson, M.K. Miller, R.M. Ulfig, R.J. Matyi, P.P. Camus, T.F. Kelly, Ultramicroscopy 73, 273 (1998)

[24] M.K. Miller, K.F. Russell, G.B. Thompson, Ultramicroscopy 102, 287 (2005)

[25] K. Thompson, D. Lawrence, D.J. Larson, J.D. Olson, T.F. Kelly, B. Gorman, Ultramicroscopy 107, 131 (2007)
[26] V.Y. Gertsman, Y.P. Lin, A.P. Zhilyaev, J.A. Szpunar, Philos. Mag. A 79, 1567 (1999)

[27] W.D. Yang, Reactor materials science, 2nd edn. (Atomic Energy Press, Beijing, 2006), p. 260. (in Chinese)

[28] B.X. Zhou, Q. Li, W.Q. Liu, M.Y. Yao, Y.L. Chu, Rare Metal Mater. Eng. 35, 1009 (2006). (in Chinese)

[29] B.X. Zhou, Q. Li, Q. Huang, Z. Miao, W.J. Zhao, C. Li, Nucl. Power Eng. 21, 439 (2000). (in Chinese)

[30] B.X. Zhou, paper present in Zirconium in the Nuclear Industry: 8th International Symposium, Philadelphia, 1989, pp. 360-373 